\title{
Study on Green Supply Chain Management of Agricultural Products Processing Enterprises of Jilin Province
}

\author{
Jie $\operatorname{Lin}^{1} \&$ Xiuying Dai ${ }^{1}$ \\ ${ }^{1}$ School of Economics \& Management, Changchun University of Science \& Technology, 7989, Weixing Road, \\ Chaoyang District, Changchun 130022, China \\ Correspondence: Jie Lin, School of Economics \& Management, Changchun University of Science \& Technology, \\ 7989, Weixing Road, Chaoyang District, Changchun 130022, China. Tel: 86-186-043-18785 E-mail: \\ sky_lj2004@163.com
}

Received: April 1, 2015

Accepted: April 24, 2015

Online Published: April 27, 2015

doi:10.5430/jbar.v4n1p45

URL: http://dx.doi.org/10.5430/jbar.v4n1p45

This paper is funded by the Youth Scientific Projects of Changchun University of Science \& Technology "Research on Green Supply Chain of Agricultural Products Processing Enterprises of Jilin Province" (No. XQNJJ-2013-14).

\begin{abstract}
Agricultural products are closely related to people's life as daily necessity, and the concern there are more and more to the quality, safety and nutrition of agricultural products. More and more people take environmental protection and resource conservation into account .And with development of supply chain management, agricultural products processing enterprises can find the road to green ecological agriculture by constructing the Green Supply Chain It's also an inevitable choice for agricultural products processing enterprises to make remarkable progress. Jilin province is one of the provinces famous for its agricultural production, agricultural products processing enterprises of Jilin province should construct Green Supply Chain.It can exploit its advantages of resource, promote a great advance and improve competition ability of the enterprise.
\end{abstract}

Keywords: Agricultural products processing enterprises, Green supply chain, Management

With the agricultural products as indispensable daily necessities to human life, consumers pay more and more attention to agricultural products' quality, safety, and nutritional value. Because of people's emphasis on environmental protection and resource conservation, and the development of supply chain management, for agricultural products processing enterprises, to adopt the green supply chain management turns to be an inevitable choice in order to achieve the long-term sustainable development. Jilin Province has rich agricultural products. Therefore, in Jilin Province the agricultural products processing enterprises can take advantage of resources to accelerate the development of enterprises and improve the competitiveness through implementing the green supply chain management.

\section{The status of development of agricultural products processing enterprises in Jilin Province}

During the past five years, the agricultural products processing industry rises at $13 \%$ above annually. As the most dynamic and promising pillar industries in Jilin Province, the agricultural products processing industrial production accounts for one third of the province's total economic output. In the year 2014, there are 3680 large-scale agricultural products processing enterprises, including 47 national leading enterprises and 494 provincial important enterprises, totally accomplishing an investment of 38.1 billion Yuan in fixed assets. The total sales revenue of agricultural products processing enterprises reach 402.8 billion Yuan, maintaining an average annual growth rate of more than $13 \%$ in five successive years. They contribute the taxes of 15 billion Yuan, achieving a rise of $10 \%$. The export delivery reaches the amount of 7.6 billion Yuan, realizing the rise of $9 \%$. It totally offers 2.75 job positions, with a rise of $2 \%$. The integrated processing level of agricultural products in Jilin Province ranks at the eighth, rising from the twelfth. 


\section{Problems in the existing supply chain management in the agricultural products processing enterprises in Jilin}

Entering the "Twelfth Five-Year Plan" period, all areas attach great importance to the development of agricultural products processing industry through strengthening the policy supports and enhancing the organization. It shows a satisfying development tendency for agricultural products processing enterprises with enlarging sizes, clustering growth, and improvement of efficiency. However, surveys indicate that there are some problems in the existing supply chain management in agricultural products processing enterprises in Jilin Province, which harm the implementation of green supply chain. These problems are mainly in these following aspects.

2.1 The agricultural products processing enterprises has no concept of green supply chain and a weak awareness of environment protection.

In Jilin Province, some agricultural products processing enterprises (especially the SMEs) have not developed a unified agreement to the application of green supply chain management. Some of them pursue for nothing but the economic benefits. Some even regard the environment protection as the opposite of enterprise development. Furthermore, some agencies and employees inside the enterprises have no awareness of sustainable development or green development. Particularly, barriers from the design, purchase, production, and marketing agencies severely block the implementation of green supply chain management in enterprises.

2.2 The supply chain has no perfect quality assurance system, without considering the concept of environment protection, safety, and green.

Some small and medium-sized agricultural products processing enterprises do not take quality control as the key of supply chain management, ignoring consumers' health and safety. The quality assurance system is far from perfect. Because of the absence of the barcode retrieving and information integration system for material production, products production, and logistics, a complete, timely, and digitalized quality control will never come true. To ignore environment protection and fail to recycle the waste will cause environmental pollution. The logistics, sales, and packaging never consider the green and environment-friendly materials or tactics. They do not take necessary actions to achieve low-carbon operations.

2.3 The separation of suppliers and the traditional supply chain mode are not conductive to the integration of green supply chain.

Due to the uniqueness of China's national conditions, suppliers of materials for agricultural products processing enterprises consist of thousands of small farmers. Most agricultural products processing enterprises and farmers adopt the traditional processing mode, i.e. operate independently without exchange of information. Some scientific ideas and tools from supply chain management theories, such as the optimized selection of suppliers, stock management, and supplier relationship management, can not apply to the supply chain management of agricultural products processing enterprises. As a result, the agricultural products supply chain is broken. A series of short chains are not conductive to the integration of supply chain members. The implementation of green supply chain management becomes impossible.

\subsection{The inefficient logistics system causes a waste of resources and energy.}

The logistics system is inefficient in Jilin Province. Especially for the fresh agricultural products supply chain, the poor technology of cold chain logistics results in a high rate of attrition, wasting lots of resources. It severely harms the green supply chain management. In Jilin Province, about $94 \%$ of agricultural products processing enterprises have their own warehouses. They seldom choose to use the third-party logistics. Unfortunately, the existing logistics system of agricultural products processing enterprises do not emphasize or use the reverse logistics, which do no good to the thorough utilization of resources, eventually causing environmental pollution.

\subsection{The lack of information technology support is not conductive to the green supply chain management.}

In the supply chain of agricultural products processing enterprises in Jilin Province, the agricultural production is kind of blindness because farmers are not good at collecting useful and timely information. As a result, the agricultural products may fail to meet the need of agricultural products processing enterprises. Furthermore, agricultural products processing enterprises do not know about the consumption market due to the lack of necessary market survey. Consequently, the quality, quantity, or size of their products can not satisfy the market demand. The insufficient use of information technology will result in an unstable supply chain, which is not good for the assurance of types and quality of materials. Accordingly, it will ruin the implementation of green supply chain in agricultural products processing enterprises. 


\section{The need for agricultural products processing enterprises applying the green supply chain management in Jilin Province}

Green supply chain management is an inevitable requirement for sustainable human development, which is appropriate for the resource-saving and environment-friendly development of Jilin Province. First of all, unlike other manufacturing enterprises, agricultural products processing enterprises, especially the food processing enterprises provide products directly to consumers. Their products' quality and safety are quite important to people's daily life. To build a green supply chain can accelerate the market response rate. To use the agility logistics, advanced cold chain management, and information management and technology can provide people with fresh and high-quality agricultural products. Secondly, by means of implementing the green supply chain management, agricultural products processing enterprises can maximize the utilization of resources and energy, reducing waste of resources, and significantly improving their market competitiveness. Finally, the implementation of green supply chain will solve the environmental pollution caused by pesticides, fertilizers, packaging, and feed additives, adapt to the internationalization of management, and further break through the green barriers to international trade.

\section{The specific measures for Jilin Province establishing the green supply chain of agricultural products processing enterprises}

In Jilin Province, agricultural products processing enterprises, especially some large enterprises, must implement the green supply chain management in order to obtain more development space. To focus on green management will win the international acceptance, help to enhance the strength of the enterprise, and improve the competitiveness in the global market.

4.1 Enhance the awareness of environment protection and resource conservation, and adopt the green and standardized management.

Establish the green supply chain management concept comprehensively and win the support of the leadership. Learn from foreign successful management experiences and adopt the advanced management mode. Since many developed countries apply the "Good Manufacturing Practice (GMP)" to management, we can learn from this advanced mode and adopt the "Hazard Analysis and Critical Control Points (HACCP)" system and the ISO9000 quality assurance system to ensure the safety and quality of agricultural products, achieving the standard management.

\subsection{The processing enterprises must ensure the green operations in the supply chain.}

The quality and safety of raw materials are the assurance of ultimate agricultural products. Therefore, we must control the quality from the original sources. We can perform scientific management of raw materials and farmers, provide necessary directions, and improve the quantity and quality of raw materials. Implement the whole-process quality control, and adopt an international-standard management system. Apply the barcode retrieving and information integration system, and achieve the comprehensive and immediate quality control.

\subsection{Use the advanced scientific technologies and perform the green production.}

Carry out the in-depth and delicate process and green design to improve the quality of products and the outputs rate of resources. Perform the technology-intensive production, and improve competitiveness of famous brands. These are important ways to improve the economic efficiency of enterprises. Currently, with the continuous development of food chemistry, biotechnology, agro-processing technology, and other related disciplines, agricultural products processing develops further at the molecular level. Besides, a number of high technologies are widely applied to agricultural products processing enterprises. Science and technology are primary productive forces. Only by relying on technologies, can agricultural products processing enterprises, at the core of the supply chain, produce high-quality and high added value products.

4.4 Develop logistics and information technology and other supporting technologies for the green supply chain management.

Use the advanced logistics management and establish the supply chain management information system. In the supply chain of agricultural products processing enterprises, establish the system based on the information of the packaging, handling, processing, delivering, and other logistics activities, and organize and manage the system properly, forming a complete supply chain, and ensuring the smoothness of the chain. The implementation of green supply chain is accompanied by the extension of the border. It can incorporate all aspects into the supply chain information management system to improve the overall response speed. 
4.5 The government encourages agricultural products processing enterprises to build the green supply chain management by policies.

The government should make full use of resources, take the time to seize the large-scale projects and support the medium-sized projects, and promote the small-sized projects. By providing necessary policy directions, the government should encourage agricultural products processing enterprises to focus on the advantageous food products, including corn, rice, and soybeans, the livestock products, including beef cattle, pigs, and chickens, and local special products, including black fungus. By this way, we can achieve the full development of Changbai Mountain brand resources, deepen the processing of agricultural products, and establish a general project system in Jilin Province.

\section{References}

Ahumada O,Villalobos J R. (2009). Application of planning models in the agri-food supply chain: A review. European Journal of Operational Research, 59. http://dx.doi.org/10.1016/j.ejor.2008.02.014

Liu Xiaowei, Wang Zhigang. (2011). The performance evaluation of green supply chain of enterprise. International Symposium on Applied Economics, Business and Development(EI),8.

Wen, Xiu-li. (2015). Analysis of green agricultural products supply chain operation model. Logistics Sci-Tech, 2.

Zhang ,Yi \& YAO Shujun. (2015). Research on Knowledge Dynamic Embedded Mechanism in Green Supply Chain Based on Regeneration Niche Theory. Science and Technology Management Research, 5. 